\title{
PERANCANGAN SISTEM INFORMASI MENTORING UNTUK PERGURUAN TINGGI
}

\author{
Reina; Irma Irawati Ibrahim; Josef Bernadi Gautama \\ Computer Science Department, School of Computer Science, Binus University \\ Jl. K.H. Syahdan No. 9, Palmerah, Jakarta Barat 11480 \\ reina@binus.edu; irma.irawati@binus.edu; jbernadi@binus.edu
}

\begin{abstract}
Mentoring supports the success of student's study in almost all colleges. Mentoring activities include consulting, mentoring and enrichment materials, and monitoring the achievement of study for all students. Along with the growing number of students, encountered several obstacles in the process of mentoring such as the limitations of time and place to hold mentoring, the availability schedule given by the mentor, and the inadequate number of mentors. Research methods used include field studies, literary studies, problem identification, and problem analysis. To provide appropriate solutions in response to the existing problems, an information system of mentoring is designed.
\end{abstract}

Keywords: information systems, mentoring, study success

\begin{abstract}
ABSTRAK
Kegiatan mentoring merupakan salah satu kegiatan yang mendukung keberhasilan studi mahasiswa pada hampir semua perguruan tinggi. Kegiatan mentoring meliputi konsultasi, pendampingan, dan pengayaan materi, serta monitoring ketercapaian studi untuk semua mahasiswa. Seiring dengan bertumbuhnya jumlah mahasiswa yang semakin besar, ditemui beberapa kendala dalam proses mentoring, yaitu keterbatasan waktu dan tempat untuk mengadakan mentoring, ketersediaan jadwal yang diberikan oleh mentor, serta jumlah mentor yang tidak memadai. Metode penelitian yang digunakan meliputi studi lapangan, studi literatur, identifikasi permasalahan, hingga analisis permasalahan.Untuk memberikan solusi yang tepat dalam menjawab permasalahan-permasalahan yang ada, dirancang sebuah sistem informasi mentoring.
\end{abstract}

Kata kunci: sistem informasi, mentoring, keberhasilan studi 


\section{PENDAHULUAN}

Dalam dunia pendidikan, belajar merupakan kegiatan utama yang harus dilakukan oleh seseorang untuk mencapai tujuannya. Keberhasilan suatu proses pembelajaran tersebut bergantung dari proses belajar yang dilakukan oleh individu tersebut, di samping faktor-faktor lain seperti usia, jenis kelamin, dan sebagainya. Salah satu parameter untuk mengukur keberhasilan belajar seorang mahasiswa, dapat dilihat dari Indeks Prestasi yang dicapai setiap semesternya. Salah satu usaha yang dilakukan oleh hampir seluruh universitas di Indonesia adalah dengan mengadakan mentoring. "Mentoring is a mutual relationship between two individuals in which a dedicated and encouraging individual volunteers his or her time to offer support to another individual in personal, academic or professional growth.” (Damanhoori, Muton, Zakaria, \& Mustaffa, 2012).

Kegiatan mentoring meliputi coaching, counseling, dan tutoring, serta monitoring ketercapaian studi mahasiswa. Dengan mengikuti program ini, diharapkan mahasiswa mampu memahami dan menguasai materi-materi kuliah, dan dapat meningkatkan prestasi belajarnya. Pada umumnya mentoring dilakukan antara mentor (orang yang membimbing), yaitu mahasiswa tingkat yang lebih tinggi dengan mentee (orang yang dibimbing), yaitu mahasiswa tingkat pertama atau kedua (Groh, 2012).

Namun ditemukan beberapa kendala dalam pelaksanaan program mentoring, seperti keterbatasan tempat pertemuan yang disediakan oleh universitas, kesesuaian waktu pertemuan mentor dan mentee, serta monitoring pelaksanaan. Seiring dengan perkembangan teknologi pada ilmu pengetahuan, pendidikan menjadi salah satu bidang yang menggunakan teknologi sebagai sarana untuk membantu proses belajar mengajar. "Over the last ten to 15 years, many organizations have moved some or all of their training programs out of the classroom and into computer-based offline and online formats for distance education" (Homitz \& Berge, 2008). Hal ini menyebabkan tidak ada batasan waktu tempat untuk melakukan kegiatan mentoring ini ."they begin to look for new and different ways to help students deal with problems related to computer-based and internet learning" (Homitz \& Berge, 2008). Dengan memanfaatkan teknologi informasi secara maksimal akan dapat membantu mahasiswa dalam mencari sumber, catatan, bahan kuliah ataupun contoh soal, secara mudah dan akurat. Bahkan saat ini, dimungkinkan perkuliahan yang dilakukan jarak jauh. Selain perkuliahan, proses mentoring dapat pula dilakukan jarak jauh (Lawanson, 2010)

Tujuan yang ingin dicapai dari penelitian ini adalah sebagai berikut: (1) mengidentifikasi dan mengumpulan informasi mengenai program mentoring pada perguruan tinggi; (2) melakukan analisis dan perancangan sistem informasi yang dibutuhkan oleh perguruan tinggi dalam menunjang proses mentoring.

Manfaat dari penelitian ini adalah sebagai berikut: (1) memiliki informasi terkait program mentoring pada perguruan tinggi; (2) memiliki perancangan sistem informasi yang dibutuhkan oleh perguruan tinggi dalam menunjang proses mentoring.

\section{METODE}

Metodologi yang akan digunakan dalam melakukan pengembangan sistem ini mengacu pada FAST Methodology yang secara keseluruhan sebagai berikut: (1) scope definition - pada tahapan ini ditentukan ruang lingkup dari proyek yang akan dikerjakan, ada beberapa proyek dilakukan bertahap jika dianggap terlalu besar setelah dilakukan penilaian di lapangan dapat melalui observasi maupun wawancara dengan pihak terkait; (2) problem analysis - melalui observasi, survei, ataupun 
wawancara pengelompokan permasalahan, potensi permasalahan, ataupun perbaikan proses dilakukan dan dianalisis; (3) requirement analysis - dari hasil analisis masalah diperolehkan serangkaian kebutuhan pengguna yang akan dibangun di dalam sebuah proyek pengembangan aplikasi; (4) logical design - agar kebutuhan pengguna mudah dimengerti baik oleh pengguna maupun pihak developer, kebutuhan-kebutuhan ini diterjemahkan kedalam beberapa model, seperti usecase, entity relational database (ERD), dan lain-lain; (5) decision analysis - pada tahapan ini diputuskan sistem yang akan dibangun; (6) physical design and integration - developer mulai membuat GUI (graphic user interface) untuk mempermudah gambaran dari sistem yang akan dibangun mendekati sistem sebenarnya dari sisi tampilan dan juga skenarionya; (7) construction and testing, dan (8) installation and delivery. Pada penelitian ini tahapan yang dilakukan mulai scope definition hingga Physical design, yang hasil akhirnya merupakan rancangan Graphic User Interface dari sistem interface yang dibangun.

\section{HASIL DAN PEMBAHASAN}

\section{Ruang Lingkup}

Sistem yang akan dibangun adalah sistem informasi mentoring untuk perguruan tinggi yang meliputi aktifitas coaching, counseling, dan tutoring. Tujuan dari pengembangan sistem informasi ini adalah untuk memberikan flesibilitas atas kendala keterbatasan waktu dan lokasi dalam memberikan mentoring. Serangkaian kegiatan observasi dilakukan untuk mengetahui kebutuhan dari sistem yang dirancang berdasarkan kebutuhan pengguna.

\section{Analisis Masalah}

Permasalahan yang mungkin timbul dari pengembangan Sistem Informasi Mentoring akademik, dapat dikelompokan dalam Tabel 1 di bawah ini:

Tabel 1 Analisis Masalah

\begin{tabular}{|c|c|c|c|}
\hline \multicolumn{2}{|c|}{ ANALISIS PENYEBAB DAN AKIBAT } & \multicolumn{2}{|c|}{ TUJUAN PERBAIKAN SISTEM } \\
\hline Masalah/Peluang & Penyebab dan Akibat & Tujuan & Solusi \\
\hline $\begin{array}{ll}\text { (1). } & \text { Kesulitan untuk } \\
\text { melakukan } \\
\text { pertemuan antara } \\
\text { mentor dan } \\
\text { mentee }\end{array}$ & $\begin{array}{ll}\text { (1). } & \text { Mentor dan mentee } \\
\text { memiliki aktifitas } \\
\text { beragam sehingga } \\
\text { sulit mencari waktu } \\
\text { yang cocok untuk } \\
\text { melakukan } \\
\text { mentoring. } \\
\text { (2). } \\
\text { Keterbatasan } \\
\text { ruangan yang } \\
\text { disediakan oleh } \\
\text { perguruan tinggi } \\
\end{array}$ & $\begin{array}{l}\text { Memberikan fleksibilitas } \\
\text { dalam melakukan } \\
\text { mentoring }\end{array}$ & $\begin{array}{l}\text { Sistem memiliki } \\
\text { fasilitas mentoring } \\
\text { online }\end{array}$ \\
\hline $\begin{array}{ll}\text { (2). } & \text { Memungkinkan } \\
\text { terjadinya } \\
\text { kehilangan data } \\
\text { hasil mentoring }\end{array}$ & $\begin{array}{l}\text { (3). Pencatatan hasil } \\
\text { mentoring masih } \\
\text { manual }\end{array}$ & $\begin{array}{l}\text { Manajemen data } \\
\text { mentoring yang lebih baik }\end{array}$ & $\begin{array}{l}\text { Sistem memiliki } \\
\text { fasilitas pencatatan } \\
\text { semua aktifitas } \\
\text { mentoring }\end{array}$ \\
\hline $\begin{array}{ll}\text { (3). } & \text { Penyajian laporan } \\
\text { hasil mentoring } \\
\text { membutuhkan } \\
\text { waktu yang cukup } \\
\text { lama }\end{array}$ & $\begin{array}{ll}\text { (4). } & \text { Pencatatan hasil } \\
\text { mentoring masih } \\
\text { manual sehingga } \\
\text { setiap laporan pun } \\
\text { dibuat manual }\end{array}$ & $\begin{array}{l}\text { Penyajian laporan } \\
\text { mentoring cepat dan } \\
\text { akurat }\end{array}$ & $\begin{array}{l}\text { Sistem memiliki } \\
\text { fasilitas laporan } \\
\text { mentoring }\end{array}$ \\
\hline
\end{tabular}




\begin{tabular}{cccr}
\hline \multicolumn{2}{c}{ ANALISIS PENYEBAB DAN AKIBAT } & \multicolumn{2}{c}{ TUJUAN PERBAIKAN SISTEM } \\
\hline Masalah/Peluang & Penyebab dan Akibat & Tujuan & Solusi \\
\hline & sesuai dengan & & \\
& kebutuhan format & \\
& laporan & \\
\hline
\end{tabular}

\section{Analisis Kebutuhan}

Berdasarkan hasil observasi penelusuran berbagai kegiatan mentoring akademik di perguruan tinggi, maka kegiatan mentoring meliputi: (1) coaching, (2) counseling, dan (3) tutoring. Dalam proses coaching, dilakukan pendampingan dari mentor kepada mentee untuk mengenalkan kehidupan kampus agar mentee dapat beradaptasi dengan baik. Counseling menitikberatkan pada konsultasi yang dilakukan mentee dalam menghadapi permasalahan secara umum. Sedangkan tutoring fokus pada pengayaan materi yang dipelajari dalam perkuliahan. Untuk melakukan kegiatan mentoring, dibutuhkan pemetaan kelompok mentor dengan mentee yang dapat dilakukan dengan mudah, terutama bagi perguruan tinggi dengan jumlah mahasiswa yang cukup besar. Selain kemudahan melakukan pemetaan, dibutuhkan pula kemudahan komunikasi antara mentor dan mentee tanpa terkendala oleh ruang dan waktu. Untuk mengukur efektifitas kegiatan mentoring, maka dibutuhkan pelaporan yang ditunjang oleh data yang akurat, untuk itu perlu disediakan fasilitas rekam jejak atas kegiatan mentoring yang telah dilakukan. Berdasarkan analisis masalah yang telah dilakukan maka dibutuhkan sebuah sistem mentoring yang mampu menyediakan fasilitas pencatatan semua kegiatan mentoring dan juga pelaporan yang dibutuhkan atas kegiatan mentoring tersebut. Kegiatan pencatatan mentoring terdiri dari pendataan mentor dan mentee, pencatatan kegiatan mentoring baik dengan fasilitas chat maupun rangkuman kegiatan. Interaksi terhadap sistem mentoring dilakukan oleh admin, mentor, dan mentee dengan role yang berbeda-beda, untuk itu perlu disediakan fasilitas login sebelum berinteraksi dengan sistem. Sebagai admin semua kegiatan dan laporan sehubungan dengan mentoring dapat diakses oleh admin. Sedangkan Mentor dapat melakukan mentoring untuk sekumpulan mentee dibawah asuhannya dan dapat melihat histori dari kegiatan tersebut serta melakukan pendataan kesimpulan kegiatan. Sedangkan Mentee fasilitas yang dapat digunakan adalah kegiatan mentoring dan juga melihat histori dari kegiatan tersebut.

\section{Logical Design}

Berdasarkan analisis kebutuhan terdapat tiga proses utama yang akan difasilitasi oleh sistem, yaitu: (1) pendataan mentor dan mentee, (2) kegiatan mentoring via chat dan (3) pendataan rangkuman kegiatan mentoring. Gambar 1 dan 2 merupakan Use Case diagram sistem informasi Mentoring. Use case tersebut menjelaskan interaksi pengguna dengan sistem. Pengguna terdiri dari tiga peran, yaitu Mentor, Mentee dan Admin. Pada gambar 1 - use case Mentor dan Mentee dapat dilihat bahwa Mentor dan Mentee dapat melakukan berbagai macam aktivitas terhadap sistem, yaitu Login, Chat, Melihat History Chat, Melihat History Rangkuman Mentoring, Melihat Informasi Mentor, Update Data Pribadi, dan Mengganti Password. Ada beberapa kegiatan tambahan yang hanya dapat dilakukan oleh Mentor, yaitu Pendataan Rangkuman Mentoring, Melihat Data Mentee, dan Melihat Informasi Mentee.

Pada Gambar 2 - Use Case Admin, beberapa aktivitas yang dapat dilakukan oleh Admin terhadap sistem adalah Login, Set Periode, Set Kategori, Set Mentor, Add/Edit Data Mentor, Set Mentee, Add/Edit Data Mentee, View Group dan Mengganti Password.

Gambar 3 menunjukan ERD-Entity Relationship Diagram untuk sistem informasi mentoring. Sistem informasi mentoring terdiri dari beberapa tabel, yaitu (1) Master table yang terdiri dari Master Mentee (ms_mentee), Master Mentor (ms_mentor), dan Master Periode (ms_periode); (2) Tabel Transaksi Chat yang terdiri dari Header Chat (chat_h) dan Detil Chat (chat_d); (3) Table Transaksi 
Mentoring yang terdiri dari Header Mentoring (mentoring_h) dan Detil Mentoring (mentoring_d).

\section{Decision Analysis}

Dengan mengacu pada kebutuhan proses mentoring, desain sistem informasi mentoring adalah sebagai berikut: (1) admin melakukan pendataan Periode Mentoring, kemudian melakukan pendataan master mentor dan mentee, serta membuat kelompok mentoring; (2) mentor dan mentee melakukan kegiatan Mentoring dapat dengan berbagai cara, yaitu tatap muka, telepon, atau memanfaatkan fasilitas Chat di sistem informasi mentoring. Semua aktivitas Mentoring tersebut, didatakan di sistem oleh Mentor; (3) sistem dibuat dengan berbasiskan web mengingat ada kebutuhan fleksibilitas dari waktu dan tempat; (4) sistem informasi mentoring sangat disarankan agar dapat terintegrasi dengan sistem informasi akademik yang telah ada, sehingga tidak terjadi redudansi data.

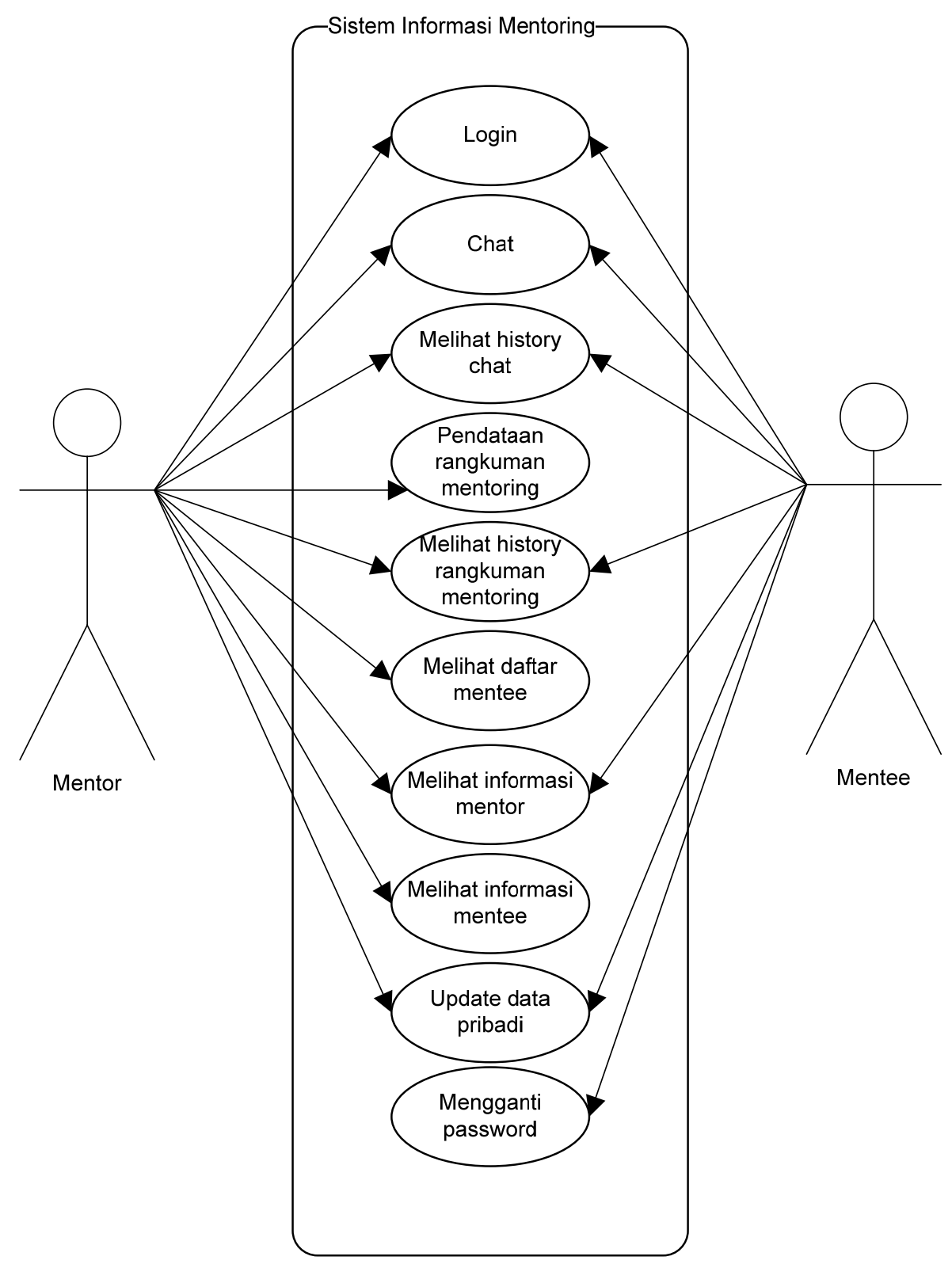

Gambar 1 Use Case Mentor dan Mentee 


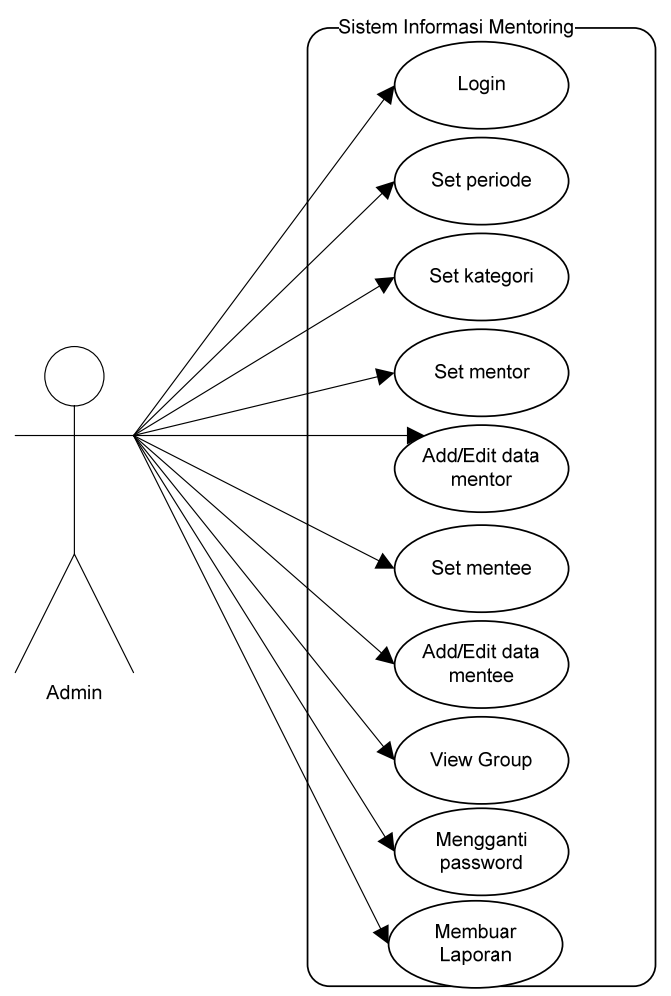

Gambar 2 Use case admin

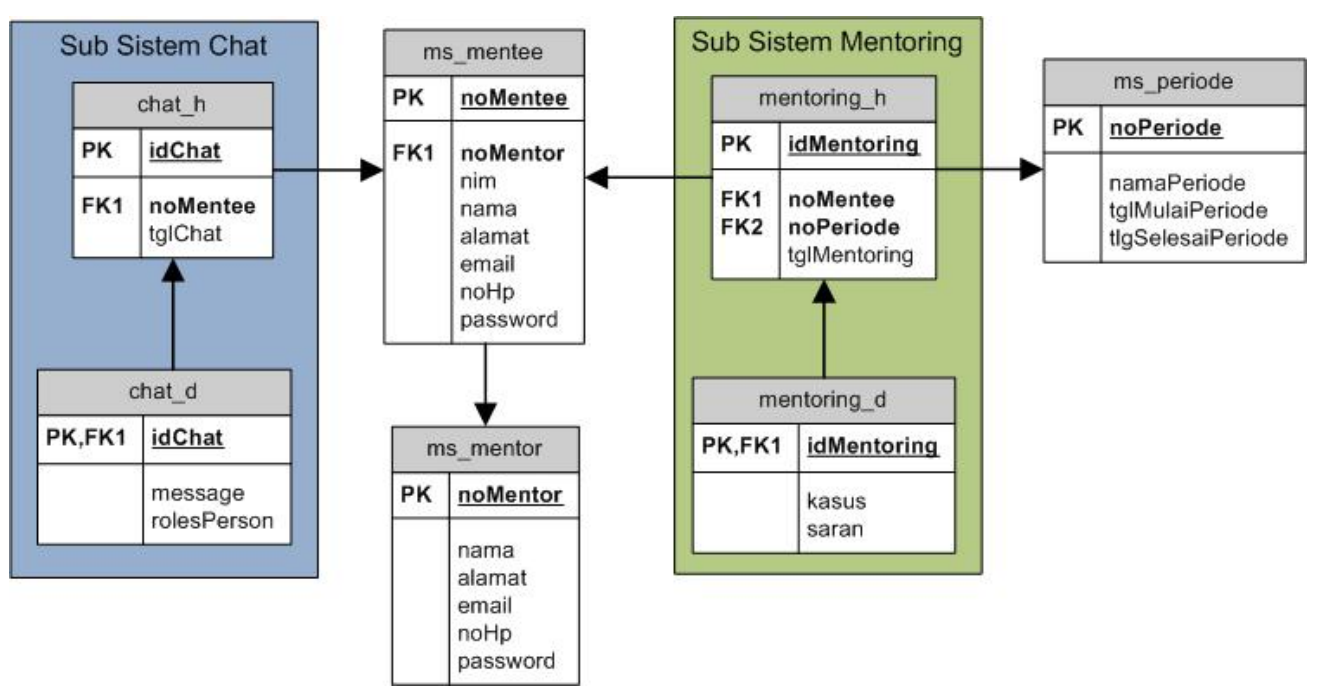

Gambar 3 ERD

\section{Physical Design}

Pada tahapan ini telah dibuat sebuah rancangan Graphic User Interface (GUI) sistem informasi mentoring yang dapat dilihat pada Gambar 4, 5, dan 6 berikut: 


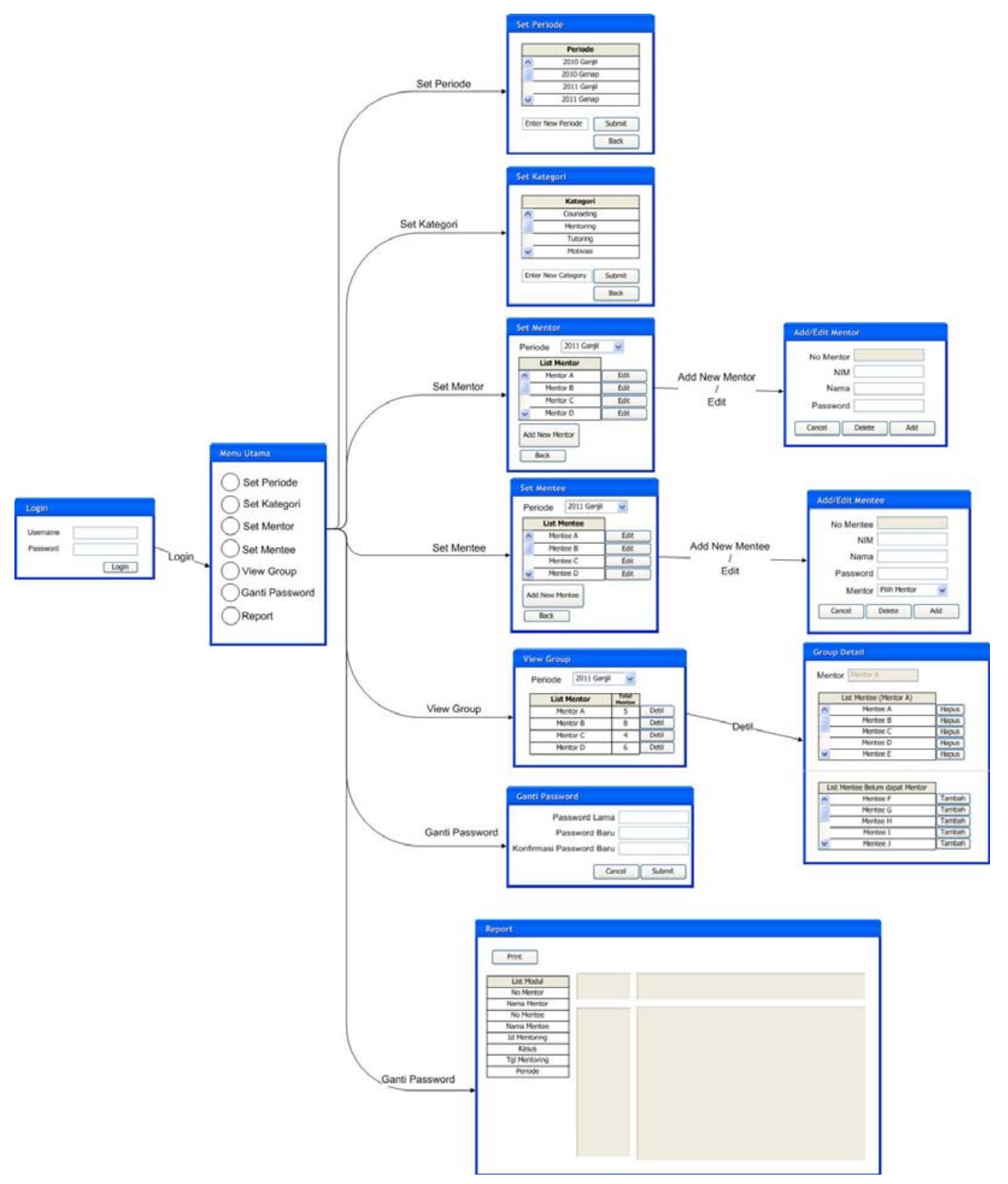

Gambar 4 Rancangan GUI Admin 
Berikut ini adalah skenario dari GUI admin: (1) Login. Layar ini akan ditampilkan saat pertama kali halaman web diakses, sebagai validasi untuk peserta mentoring. Halaman ini juga digunakan sebagai penentu role user berperan sebagai admin / mentor / mentee; (2) Menu utama. Menu yang dapat di akses jika user login dengan role admin; (3) Menu Set Periode. Pada menu ini admin dapat memilih periode yang sedang berjalan, dan menginput periode baru; (4) Menu Set Kategori. Pada menu ini, admin mendatakan jenis-jenis kategori yang dapat dipilih oleh mentor dalam menginput summary kegiatan; (5) Menu Set Mentor Admin. Pada menu ini admin dapat melihat daftar mentor yang terdaftar pada program mentoring. Pada halaman ini juga terdapat tombol untuk menambah atau tombol untuk mengedit data mentor; (6) Sub Menu Add/Edit Mentor. Jika tombol add new mentor di klik, makan akan di generate nomor mentor baru, dan mentor baru dapat didatakan, tetapi jika di pilih edit, maka, tampilan akan menunjukan data mentor. Halaman ini juga akan berguna sebagai pereset password, jika ada mentor yang lupa password; (7) Set Mentee. Pada menu ini admin dapat melihat daftar mentee yang terdaftar pada program mentoring. Pada halaman ini juga terdapat tombol untuk menambah atau tombol untuk mengedit data mentee; (8) Sub Menu Add/Edit Mentee. Jika tombol add new mentee di klik, makan akan di generate nomor mentee baru, dan mentee baru dapat didatakan, tetapi jika di pilih edit, maka, tampilan akan menunjukan data mentee. Halaman ini juga akan berguna sebagai pereset password, jika ada mentee yang lupa password; (9) Menu View Group. Pada menu ini ditampikan list kelompok berdasarkan nama mentor; (10) Sub Menu Group Detil. Pada sub menu ini, Admin dapan melakukan pemetaan siapa saja mentee pada mentor yang dipilih. Mentee yang sudah terdaftar, dapat di hapus, dan mentee yang belum memiliki mentor dapat ditambahkan; (11) Menu Ganti Password. Menu ini digunakan untuk merubah password user; (12) Menu Report. Form ini digunakan untuk membuat laporan. Admin dapan memilih format laporan yang diinginkan dengan memindahkan attribute yang ada dalam list modul ke dalam kolom atau baris yang telah disediakan.

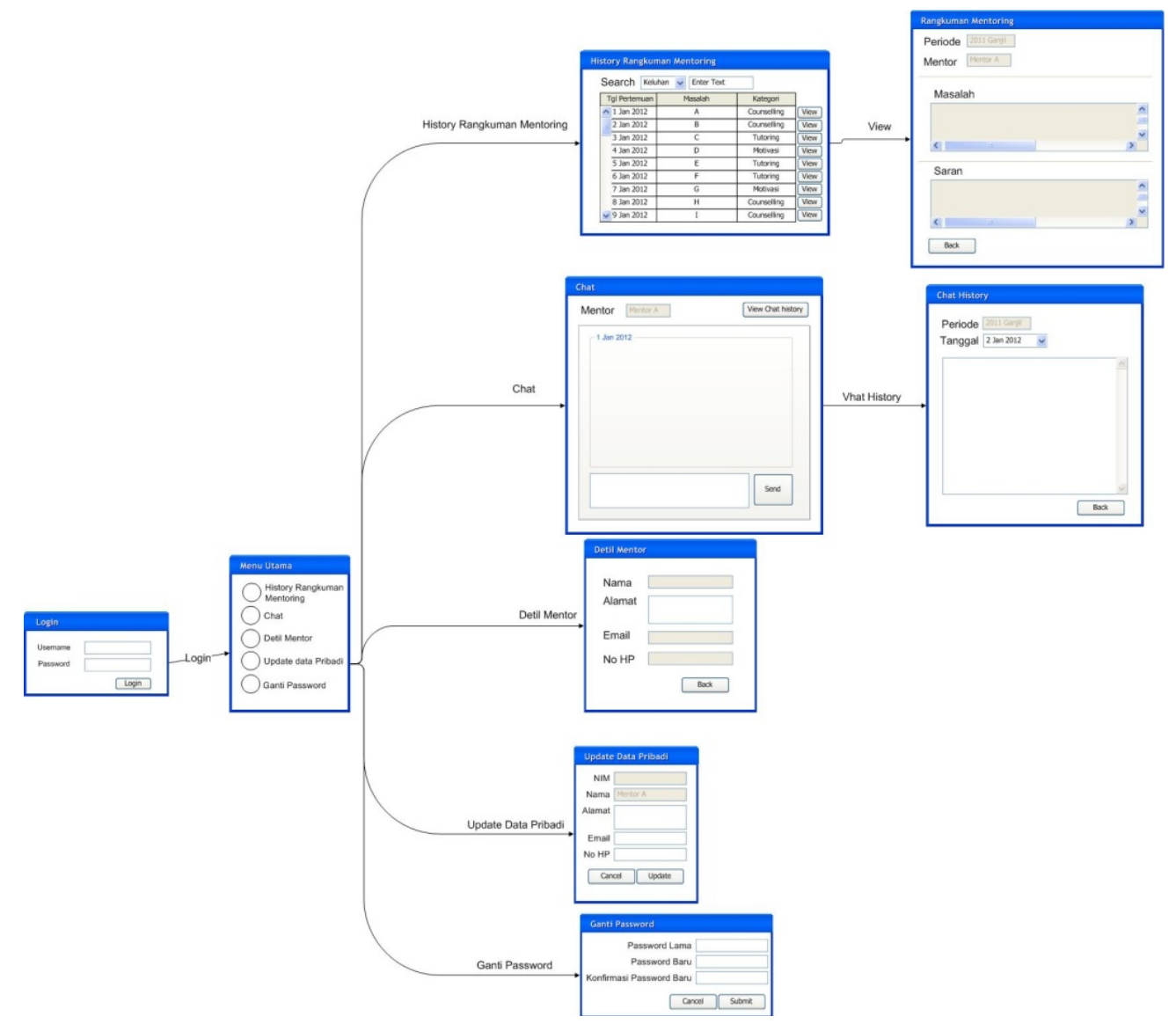

Gambar 5 Rancangan GUI Mentee 
Berikut ini adalah skenario dari GUI Mentee: (1) Menu Utama Mentee. Menu yang dapat di akses jika user login dengan role Mentee; (2) Menu history rangkuman mentoring. Mentee dapat melihat list history pertemuannya yang telah dilakukan dengan mentornya; (3) Sub Menut rangkuman mentoring. Pada menu ini, mentee dapat melihat detil pertemuannya pada tanggal tertentu, sehingga dapat mereview kembali saran yang diberikan oleh mentor; (4) Menu chat. Pada menu ini, mahasiswa dapat chatting dengan mentor, untuk meminta saran atau pendapat untuk permasalahan yang sedang dihadapi; (5) Sub Menu history Chat. Pada menu ini mentee dapat melihat history chat yang sedang pernah dilakukan dengan mentor; (6) Menu Detil Mentor. Menu ini menampilkan data pribadi mentor pada periode berjalan; (7) Menu update data pribadi. Layar ini digunakan untuk mengupdate data pribadi mentor.

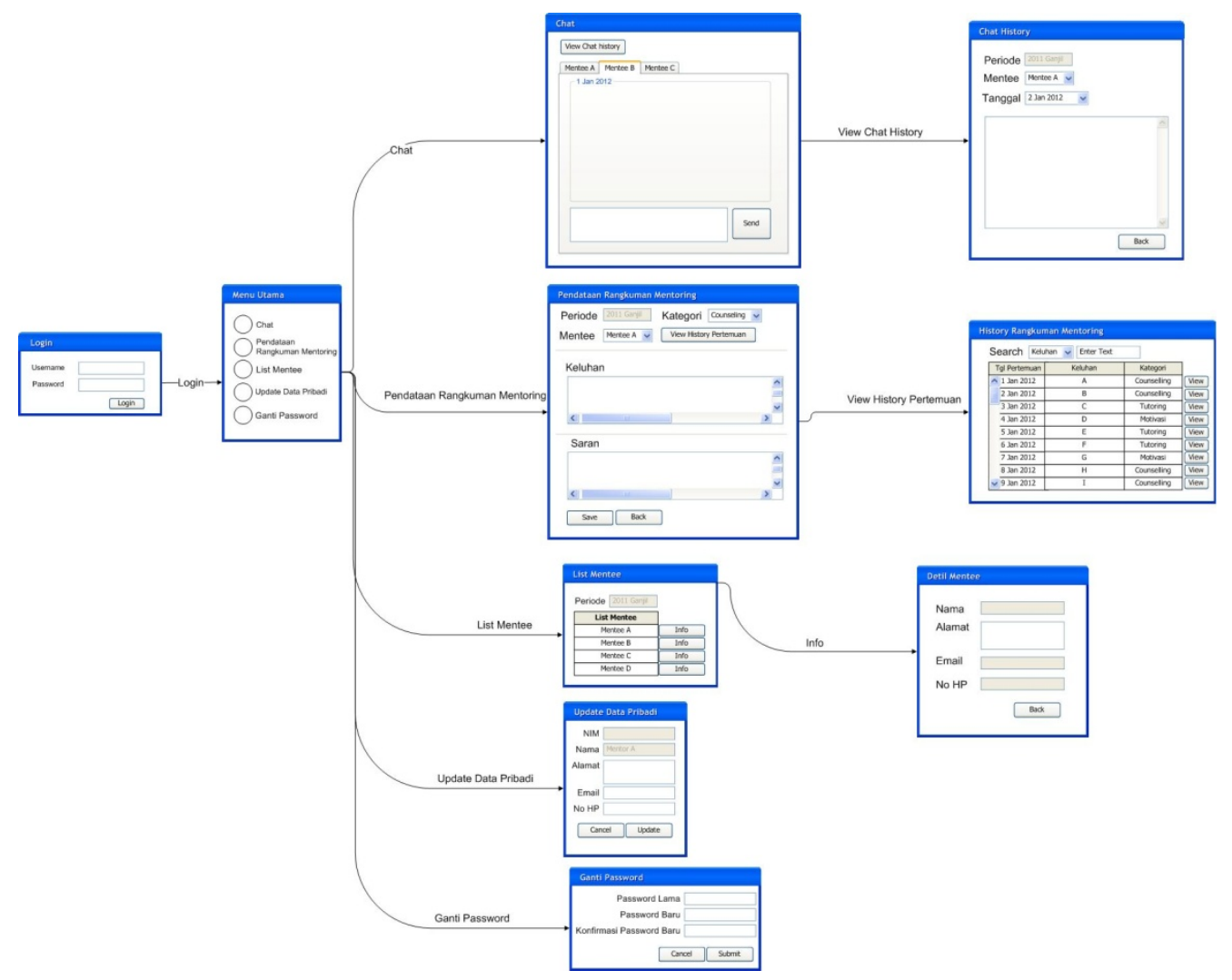

Gambar 6 Rancangan GUI Mentor

Berikut ini adalah skenario dari GUI Mentor: (1) Menu Utama. Menu yang dapat di akses jika user login dengan role Mentor; (2) Menu Chat. Pada menu ini, mentor dapat memilih mentee yang diajak bicara, dan dapat melihat history chat setiap menteenya dengan mengklik tombol "lihat history chat.”; (3) Sub Menu History Chat. Pada menu ini, mentor dapat melihat history chat per mentee, per tanggal tertentu, sehingga mentor dapat melihat kembali saran yang diberikan pada pertemuan sebelumnya; (4) Menu Pendataan Rangkuman Mentoring. Layar ini digunakan untuk menulis rangkuman pertemuan mentoring yang sudah dilakukan. Mentor dapat memilih kategori pada pertemuan tersebut. Sub Menu History Mentoring. Pada layar ini, mentor dapat melihat pertemuan yang pernah terjadi dengan mentee tertentu. Jika tombol view di klik, maka tampilan akan kembali ke layar pendataan rangkuman mentoring, dengan keluhan dan saran yang ada di database; (5) Menu List Mentee. Pada layar ini, mentor dapat melihat nama nama menteenya; (6) Sub Menu Detil Mentee. Layar ini tampil jika pada layar list mentee, ditekan tombol info. Layar ini menampilkan informasi data pribadi dari mentee; (7) Menu Update Data Pribadi. Layar ini digunakan agar mentor dapat mengupdate data pribadinya. 


\section{PENUTUP}

Penelitian ini menyimpulkan bahwa kegiatan mentoring dapat dilakukan jarak jauh dengan bantuan sistem informasi mentoring. Melalui sistem informasi mentoring, mentor dan mentee diberikan kemudahan dalam melakukan kegiatan mentoring, sehingga ruang dan waktu tidaklah menjadi kendala. Perguruan tinggi dengan jumlah kelompok mentoring yang cukup banyak dapat memanfaatkan sistem informasinya sehingga kegiatan mentoring dapat berjalan secara menyeluruh dan efektif. Hasil perancangan ini disarankan untuk dikembangkan lebih lanjut menjadi sebuah sistem aplikasi yang dapat dipakai di perguruan tinggi. Penelitian ini masih dapat dikembangkan ke tahapan penelitian selanjutnya dengan menambahkan fasilitas sesuai dengan kebutuhan pada masing-masing perguruan tinggi.

\section{DAFTAR PUSTAKA}

Damanhoori, F., Muton, N. A., Zakaria, N., \& Mustaffa, N. (2012). E-mentoring System Development using ARCS Motivational Strategies. International Journal of Smart Home .

Groh, J. L. (2012). Implementation of Group Mentoring Program for Undergraduate Woman in Engineering. WIEP .

Homitz, D. J., \& Berge, Z. L. (2008). Using e-mentoring to sustain. Emerald, 326-335.

Lawanson, R. (2010). Mentoring and developing Leaders for the Future. Personal Mentoring Journal . 